Çukurova Üniversitesi Mühendislik Mimarlık Fakültesi Dergisi, 34(4), ss. 91-103, Aralık 2019

Cukurova University Journal of the Faculty of Engineering and Architecture, 34(4), pp. 91-103, December 2019

\title{
Türkiye'de İller Arası Otomobil Yolculuklarının Çekim Yöntemi ile Modellenmesi ve CBS Ortamında İncelenmesi
}

\author{
Yaşar VITTOŞOĞLU ${ }^{* 1}$, H. Canan GÜNGÖR ${ }^{2}$, Polat YALINIZ ${ }^{1}$ \\ ${ }^{1}$ Kütahya Dumlupınar Üniversitesi, Mühendislik Fakültesi, İnşaat Mühendisliği Bölümü, \\ Kütahya \\ ${ }^{2}$ Necmettin Erbakan Üniversitesi, Havacılık ve Uzay Bilimleri Fakültesi, Uzay ve Uydu \\ Bilimleri Bölümü, Konya
}

Geliș tarihi: 15.02 .2019

Kabul tarihi: 20.12.2019

$\ddot{\mathbf{O} z}$

Literatürde başlangıç-son (O-D) matrislerini elde etmek için birçok model olmasına rağmen, ev anketlerini veya yol kenarı görüşmelerini esas alan yaklaşımların kullanılması pahalıdır. Bu nedenle, O-D matrislerini elde etmek için daha ucuz olan yöntemler geliştirilmiştir. Bu yöntemlerden birisi Bell tarafından geliştirilmiş olup, yolculuk matrislerini taşıt sayımlarından elde etmektedir. İller arası otomobil yolculuk matrisini bulmak için bu model kullanıldıktan sonra, çekim esaslı bir yolculuk dağıtımı modeli geliştirilmiştir. Elde edilen matris, daha sonra mekânsal analizleri gerçekleştirmek için Coğrafi Bilgi Sistemleri (CBS) ortamına aktarılmışıtır.

Anahtar Kelimeler: O-D matris tahmini, Coğrafi Bilgi Sistemleri, İller arası otomobil yolculukları

\section{Modeling Intercity Car Travels in Turkey with the Gravity Method and Analyzing them in GIS Environment}

\begin{abstract}
Although there are many models for obtaining origin-destination (O-D) matrices in the literature, using approaches based on home surveys or roadside conservations is expensive. Thus, various methods that are cheaper have been developed to obtain O-D matrices. One of these methods has been developed by Bell, and obtains travel matrices from vehicle counts. After this model was used for finding the intercity car travel matrix, a gravity based travel distribution model was developed. The matrix obtained was then transferred to Geographic Information Systems (GIS) environment for realizing spatial analyses.
\end{abstract}

Keywords: O-D matrix estimation, Geographic Information Systems, Intercity car travels

\footnotetext{
"Sorumlu yazar (Corresponding author): Yaşar VİTOŞOĞLU, yasar.vitosoglu@dpu.edu.tr
} 


\section{GíRiş}

Mevcut verilerin miktarı ve tutarlılı̆̆ı, ulaştırma ile ilgili doğru ve sağlıklı kararların alınmasında oldukça önemlidir. Ayrıca, bu bilgilerin uygun bilgi sistemleri kullanılarak depolanması, değerlendirilmesi ve analiz edilmesi, karar vericilerin etkin politikalar oluşturmasında önemli bir rol oynar. $\mathrm{Bu}$ bağlamda, Coğrafi Bilgi Sistemleri (CBS), mekânsal analizlerin gerçekleştirilmesi için kullanılan etkili araçlardan biridir. Dolayısıyla, Türkiye'de gerçekleştirilen iller arası otomobil yolculuklarına ilişkin bilgilerin değerlendirilmesi için bu çalışmada da CBS'den yararlanılmıştır. $\mathrm{Bu}$ amaçla iller arası otomobil yolculuğu matrisi CBS ortamına aktarılmıştır. Böylece karşılaştırma ve sorgulamaları yapmak için bu matrisi görsel bir ortamda değerlendirmek mümkün olmuştur.

Başlangıç-son (O-D) matrisleri, birçok yolculuk analizi için temel girdilerden biri olup bu matrisleri tahmin etmek için çeşitli yöntemler kullanılmaktadır. Ancak, ev anketlerini ya da yol kenarında gerçekleştirilen görüşmeleri esas alan yöntemlerin kullanılması pahalı ve zaman alıcı olmaktadır. $\mathrm{Bu}$ yüzden, O-D matrislerini teşkil etmek için pahalı ve zaman alıcı olmayan çeşitli yöntemler geliştirilmiştir.

Karayollarındaki taşıtların sayısı, yolculuk matrisi ile araç kullananların güzergâh seçimine ilişkin verdikleri kararların bir bileşkesi olup sayım yapılan karayolu bağlantılarını kullanan tüm O-D çiftleri hakkında bilgi verirler.

Ayrıca, trafiği aksatmadan ve kolay bir şekilde elde edildiklerinden oldukça cazip bir veri kaynağıdır. Dolayısıyla, 1980'li yılların başından itibaren taşıt sayımlarından yolculuk matrislerinin oluşturulması düşüncesi, araştırmacıların dikkatini çekmiş ve bu konuda çeşitli metotlar ileri sürülmüştür. Türkiye'de iller arası otomobil yolculuklarına dair O-D matrisinin elde edilmesinde yararlanılan model, M. G. H. Bell tarafından 1983 yılında geliştirilmiş olup bu metotlardan birisidir [1,2].

\section{M. G. H. BELL TARAFINDAN GELISSTIRILEN MODEL}

$\mathrm{N}$ tane bölgenin bir karayolu ağıyla birbirine bağl1 olduğu kabul edilirse, yolculuk matrisi $\mathrm{N}^{2}$ öğeden meydana gelir. Şayet bölge içindeki yolculuklar göz ardı edilirse, yolculuk matrisindeki öğe sayısı $\mathrm{N}^{2}$ - N olur. Taşıt sayımlarından bir O-D matrisini oluşturan bu $\mathrm{N}^{2}$ sayıdaki öğenin bulunabilmesi için, her bir başlangıç noktasından her bir son noktasına gerçekleştirilen yolculukların takip ettikleri güzergâhlar önceden belirlenmelidir. Eğer $\mathrm{i}$ bölgesinden $\mathrm{j}$ bölgesine gerçekleştirilen yolculukların a bağlantısını kullanma ihtimali ya da oranı $\mathrm{p}_{\mathrm{ij}}^{\mathrm{a}}$ ile belirtilirse, bu bağlantı üzerinde meydana gelen trafik akımı $\left(\mathrm{V}_{\mathrm{a}}\right)$, bölgeler arasında gerçekleştirilen tüm yolculukların o bağlantıyı kullanan kısımlarının toplamı olacaktır. Bu, matematiksel olarak Eşitlik 1 ile ifade edilebilir:

$V_{a}=\sum_{i j} T_{i j} p_{i j}^{a} \quad 0 \leq p_{i j}^{a} \leq 1$

$\mathrm{p}_{\mathrm{ij}}^{\mathrm{a}}$ olasılıkları, karmaşıklık seviyeleri birbirinden farklı olan çeşitli yolculuk ataması yöntemlerinden biri ile elde edilebilir. $\mathrm{Bu}$ atama yöntemlerinin karmaşıklık seviyeleri ise, hep-ya da-hiç atamasından denge atamasına doğru gidildikçe artar. Sonuç olarak, bütün $\mathrm{p}_{\mathrm{ij}}^{\mathrm{a}}$ oranları ve gözlenmiş taşıt sayımları $\left(\mathrm{V}_{\mathrm{a}}\right)$ verildiğinde, problemin $\mathrm{L}$ tane simültane doğrusal denklem takımından belirlenecek $\mathrm{N}^{2}$ sayıda $\mathrm{T}_{\mathrm{ij}}$ bilinmeyeni olacaktır. Burada L, taşıt sayımlarının yapıldığı karayolu bağlantılarının toplam sayısını belirtmektedir.

Trafik sayımlarından yolculuk matrisini elde etmek için yararlanılan atama yöntemleri, iki ana grupta sinıflandırılabilir. Birinci gruba dâhil olan atama yöntemleri, her bir güzergâhı seçen sürücülerin sayısının veya oranının bağlantılar üzerindeki akım düzeylerine bağlı olmadığını varsayar. Bu gruba dâhil olan atama yöntemlerinin çok bilinen örneği, hep-ya da-hiç atamasıdır ve bu yaklaşımda $\mathrm{p}_{\mathrm{ij}}^{\mathrm{a}}$ olasılıkları Eşitlik 2'de verildiği gibi tanımlanır: 


$$
p_{i j}^{a}=\left\{\begin{array}{c}
1 \quad \text { Eğer i başlangıç noktasından } \\
\text { j son noktasına yapılan } \\
\text { yolculuklar a bağlantısını } \\
\text { kullanıorsa } \\
0 \text { Kullanmıyorsa }
\end{array}\right.
$$

Salt stokastik olan atama yöntemleri de birinci grupta yer alırlar. Ancak, $\mathrm{p}_{\mathrm{ij}}^{\mathrm{a}}$ olasılıkları bu durumda 0 ile 1 arasında çeşitli değerler alabilir. Diğer taraftan, ikinci gruba dâhil olan atama yöntemleri tıkanıklık etkisini dikkate alırlar. $\mathrm{Bu}$ nedenle, her bir O-D çifti arasında gerçekleştirilen yolculukların herhangi bir bağlantıdan geçme ihtimali, aynı zamanda o bağlantı üzerindeki araç miktarına bağlıdır. Denge ve stokastik kullanıcı dengesi atama yaklaşımları, bu grupta yer alırlar.

Prensipte, $\mathrm{N}^{2}$ sayıda birbirinden bağımsız ve birbiriyle uyumlu taşıt sayımı, tek bir $\mathrm{T}$ yolculuk matrisini belirlemek için gereklidir. Bununla birlikte, uygulamada, taşıt sayımlarının sayısı $T_{i j}$ bilinmeyenlerinin sayısından çok daha azdır. Bu yüzden, ağa atandıkları zaman, genellikle gözlenen taşıt sayımlarıyla tutarlı sonuçlar veren birden çok sayıda yolculuk matrisi elde edilecektir. Bu durum, bir O-D matrisini elde etme problemi için tek bir çözümün bulunamayacağı anlamına gelir. $\mathrm{Bu}$ problemi çözmek için, iki farklı yaklaşımdan yararlanılabilir. İlk yaklaşımda, belirlenecek matris için elverişli olan çözümlerin kümesi, bir çekim veya doğrudan talep modeli tarafindan sağlanan belirli bir yapının probleme ilave edilmesiyle kısıtlanır. İkinci yaklaşımda ise, bir O-D matrisini belirlemek için gerekli olan minimum düzeydeki ek bilgiyi sağlamak üzere, maksimum olasılık ya da entropi maksimizasyonu gibi temel prensiplerden istifade edilir [3].

Robillard [4], Hogberg [5] ve LeBlanc [6] tarafından gerçekleştirilen çalışmalar ilk yaklaşımı izlemiştir. Öte yandan, Wilson [7], Van Zuylen ve Willumsen [8] ile McNeil ve Hendrickson [9] O-D matrislerini oluşturmak için entropi maksimizasyonu yöntemlerini benimsemiştir. Diğer taraftan, bilgi minimizasyonu modeli [8], genelleştirilmiş en küçük kareler modeli [10] ve Bayes modeli [11] gibi diğer yöntemler de bu amaç için kullanılmaktadır. $\mathrm{Bu}$ modellerin uygulanan teoriye dayalı kendi karakteristik özellikleri ve uygulama koşulları vardır. Bundan başka, Yang [12], son yıllarda gözlenmiş bağlantı akımlarından O-D matrislerinin tahmin edilmesi için iki seviyeli bir formülasyon geliştirmiştir. Ayrıca, etkili algoritmalar kullanılarak dinamik O-D matrislerini tahmin etmek için çeşitli araştırmacılar tarafindan başka çalışmalar da gerçekleştirilmiştir [13-16].

Bell tarafından geliştirilen model, esasında modifiye edilmiş bilgi minimizasyonu modeline benzemektedir. Eğer güzergâh seçimi oranları ya da olasılıkları tam olarak bilinmiyorsa, bilgi minimizasyonu modeli, tahmin sonuçları istikrarlı olmadığından uygun değildir. $\mathrm{Bu}$ yüzden, Van Zuylen ve Willumsen [8], geçmiş yolculukların toplam sayısı ile gerçek yolculuklar arasındaki farkı düzeltmek için bilgi minimizasyonu modelini modifiye etmişlerdir. Bell tarafından kullanılan modifiye edilmiş bilgi minimizasyonu modelinin yapısı, Eşitlik 3'te verilmektedir:

$V_{a}=\sum_{i j} t_{i j}^{o} \tau\left(\prod_{a} X_{a}^{p_{i j}^{a}}\right) p_{i j}^{a}$

Burada;

$\mathrm{V}_{\mathrm{a}}=$ sayım yapılan a bağlantısı üzerinde gözlenen taşıt sayısı,

$\mathrm{t}_{\mathrm{ij}}^{\mathrm{o}}=\mathrm{i}$ ve $\mathrm{j}$ bölgeleri arasında gerçekleştirilen yolculukların başlangıç için kabul edilen değeri,

$\tau=$ bir kalibrasyon sabiti,

$\mathrm{X}_{\mathrm{a}}=$ tahmin edilecek parametrelerin vektörü,

$\mathrm{p}_{\mathrm{ij}}^{\mathrm{a}}=\mathrm{i}$ ve $\mathrm{j}$ bölgeleri arasında gerçekleştirilen yolculukların sayım yapılan a bağlantısını kullanma ihtimalidir.

Daha sonra $\tau$ ve $X_{a}$ parametreleri, yinelemeli bir süreçte bağlantı akımı kısıtlarını sağlamak suretiyle çözülebilir. $\tau$ Değeri için kullanıcı tarafından başka değerler tanımlanmadığı sürece, $\mathrm{X}_{\mathrm{a}}$ parametreleri başlangıç olarak 1'e eşitlenerek bu değer Eşitlik 4'te verilen denklem yardımıyla belirlenebilir: 


$$
\tau=\frac{\sum_{a} V_{a}}{\sum_{a} \sum_{i j} p_{i j}^{a}}
$$

Sonraki aşamalarda, $\tau$ değeri, tanımlanan veya yukarıdaki eşitlik yardımıyla belirlenen değerinde sabit tutulur. Diğer taraftan, $X_{\mathrm{a}}{ }^{\prime}$ ların başlangıç için tahmin edilen değerlerinin çok sayıda iterasyon gerçekleştirilerek düzeltilmesi, çözüm prosedürünü oluşturur. Sayım yapılan bütün bağlantılar için her bir iterasyonda, bir $\mathrm{h}_{\mathrm{a}}$ düzeltme faktörü hesaplanır. Daha sonra, bu düzeltme faktörü, aşağıda verilen formülde gösterildiği gibi, $X^{\prime}{ }_{a}$ değerini elde etmek için $X_{a}$ teriminin başlangıçtaki tahmini değerine ilave edilir: (Eşitlik 5)

$\mathrm{X}_{\mathrm{a}}^{\prime}=\mathrm{X}_{\mathrm{a}}+\mathrm{h}_{\mathrm{a}}$

$\mathrm{h}_{\mathrm{a}}$ değerlerinin belirlenmesinde yararlanılan formül ise aşağıda verilmektedir: (Eşitlik 6)

$$
h_{a}=\frac{V_{a}-\sum_{i j} t_{i j}^{o} \tau\left(\prod_{a} x_{a}^{p_{i j}^{a}}\right) p_{i j}^{a}}{\sum_{i j} t_{i j}^{o} \tau_{i j}^{a^{2}}\left(\prod_{b \neq a} x_{b}^{p_{i j}^{b}}\right) X_{a}^{\left(p_{i j}^{a}-1\right)}}
$$

Sayım yapılan bütün bağlantılar için $h_{a}$ değerlerini yinelemeli olarak belirleme işlemi, bütün bağlantılar üzerinde gözlenen ve tahmin edilen taşıt sayımları arasındaki fark kullanıcı tarafından belirtilen sınırlar içinde kalıncaya kadar sürer. $\mathrm{X}_{\mathrm{a}}$ Terimlerinin sonuncu değerleri tüm bağlantılar için belirlendikten sonra, yolculuk matrisinin öğeleri aşağıdaki eşitlikten bulunur: (Eşitlik 7)

$$
T_{i j}=\pi_{i j}^{o} \prod_{a}\left(X_{a}\right) p_{i j}^{a}
$$

En sonunda, yolculuk matrisinin bütün $\mathrm{T}_{\mathrm{ij}}$ öğeleri belirlenmiş ve O-D matrisi elde edilmiş olur [1,2].

\section{TÜRKIYE'DE ILLLER ARASI OTOMOBIL YOLCULUĞU MATRISINININ BELIRLENMESI}

Türkiye, Asya ile Avrupa arasında uzanan stratejik bir konuma sahip olup $783.356 \mathrm{~km}^{2}$ 'lik yüzey alanıyla oldukça büyük bir ülkedir. 2015 Yılında gerçekleştirilen nüfus sayımına göre Türkiye'nin nüfusu 78.741.053'tür ve bu nüfusun \%73,4'ü kentsel alanlarda yaşamaktadır [17].

Türkiye, idari amaçlar için 81 ile bölünmüştür. Her il ilçelere bölünmüş olup, ilçelerin sayısı 923'tür. $\mathrm{Bu}$ ilçeler, $66.774 \mathrm{~km}$ uzunluğunda bir karayolu ağıyla birbirine bağlıdır. Bu karayolu ağı, otoyollar, devlet yolları ve il yollarından oluşmaktadır. Devlet yollarının, il yollarının ve otoyolların uzunlukları, sirasiyla $31.106 \mathrm{~km}$, $33.513 \mathrm{~km}$ ve $2.155 \mathrm{~km}$ 'dir. Buna ilave olarak, Türkiye'de karayolu yolcu taşımacılığının payı, yaklaşık \%92'dir [18].

Çalışmanın gerçekleştirilmesi için illere dayalı bölgeleme yapılmış ve 2015 yılı için iller arası otomobil yolculukları matrisinin belirlenmesinde 81 ilin tümü göz önüne alınmıştır. Bu amaçla teşkil olunan ve Transport Programındaki Bhnet Alt Programı kullanılarak kodlanan karayolu ağ1 epeyce ayrıntılı olup, 716 bağlantı, 269 düğüm noktası ve 81 bölgeden meydana gelmektedir [19]. Bu ağ, Şekil 1'de gösterilmektedir. Atama yöntemi olarak, hep-ya da-hiç algoritması kullanılmıştır. İl merkezleri olan şehirlerin arasındaki uzaklıklar, en kısa güzergâhları belirlemede maliyet parametreleri olarak alınmıştır. Böylece, hep-ya da-hiç ağaçları ve en kısa yollar bu maliyet parametreleri dikkate alınmak suretiyle Bhtree Alt Programı kullanılarak teşkil edilmiştir. Sonuç olarak, $p_{i j}^{\mathrm{a}}$ olasılıkları, bu hep-ya da-hiç ağaçlarından elde edilmiştir. Buna ek olarak, hızların tüm bağlantılar için aynı olduğu varsayılmış ve $90 \mathrm{~km} / \mathrm{s}$ değeri kullanılmıştır.

İller arasında gerçekleştirilen otomobil yolculuklarının tahmin edilmesi için, eksenler bazında verilen otomobil ya da taşıt sayımlarından O-D matrisleri teşkil edebilen ve Transport Programında bulunan Vmat Altprogramından 
faydalanılmıștır [19]. Bu altprogramın çalışma prensibi Bell tarafından geliştirilen modele dayanmaktadır.

Transport Programı, Fortran dilinde yazılmış olup Halcrow Fox Firması tarafından geliştirilmiştir. Bu program, kullanıcıların yüksek kapasiteli ve hızlı bilgisayarlara başvurma gereği duymaksızın etkili analitik yöntemleri uygulamalarına olanak tanımaktadır. Bu yöntemlerden bazıları şu şekilde özetlenebilir: yolculuk dağıtımı modellerinin otomatik kalibrasyonu, logit model türel dağılım analizi, trafik sayımlarından yolculuk matrisi tahmini ve denge ataması. Program, ortak dosyalar aracılığıyla birbirine bağlanan birbirinden bağımsız modüller olarak tasarlanmıştır. Dolayısıyla program, kullanıcının uygulamasına uygun bir model oluşturmasını sağlamak için bir dizi bağımsız alt dosyalar oluşturmasına imkân verir. Programın dosya biçimi basit olduğundan, bu dosyalara diğer programlardan erişmek kolaydır. Ayrıca program, daha başka programların ilave edilmesine de imkân vermektedir.

Daha önce de bahsedildiği gibi, trafik sayımlarından matrislerin tahmin edilmesinde, Vmat Altprogramı kullanılır. Bu program, üç altprogramdan oluşur. Vmat1 Altprogramı, Vmat3 Altprogramına girdi olacak veri dosyalarını üretmek için kullanılan iki programdan birincisidir. Vmat1 Programının temel amac1, her bir başlangıç-son çifti arasındaki yolculukların her bir sayım noktasından geçme olasılığını tanımlamaktır. Vmat2 Altprogramı, Vmat3 Altprogramına girdi olacak veri dosyalarını üretmek için kullanılan iki programdan ikincisidir. Bu ikinci programın amacı, trafik sayımları için bir veri dosyası oluşturmaktır. Vmat3 Altprogramı, girilen trafik sayımları ve güzergâh olasılıklarının yanında, eğer gerekli ise girilen yolculuk uzunluğu dağılımı ile uyumlu yolculuk matrisini meydana getirir. $\mathrm{Bu}$ programin temel amac1, NewtonRaphson tekniğini kullanarak ayrı ya da grup sayım yerlerindeki trafik sayımlarının girdi dosyalarından ve güzergâh olasılıklarından en muhtemel yolculuk matrisini oluşturmaktır [19].
Bilindiği gibi, Vmat Altprogramı, başlangıç matrisinin iyi tanımlanmış olması durumunda daha iyi sonuçlar verir. Başlangıç matrisi, genel olarak daha önceki çalışmalardan elde edilen matrisler kullanılarak oluşturulabilir. Öte yandan, Türkiye'de önceki yıllarda 81 il için ev anketlerini veya yol kenarı görüşmelerini esas alan böyle bir çalışma gerçekleştirilmediğinden iller arası otomobil yolculuklarına dair başlangıç matrisinin teşkil edilmesi için Çekim Modelinin prensiplerinden istifade edilmiştir. Bunun için, bir $\mathrm{i}$ ilinden bir $\mathrm{j}$ iline gerçekleştirilen otomobil yolculuklarının, i ile $\mathrm{j}$ illerinin nüfuslarının üstel fonksiyonlarının çarpımları ile doğru orantılı ve bu iki ilin arasındaki mesafenin üstel bir fonksiyonu ile ters orantılı olduğu kabul edilmiştir. Bu ifade, Eşitlik 8'de daha açık bir şekilde özetlenebilir:

$\mathrm{t}_{\mathrm{ij}}^{\mathrm{o}}=\mathrm{k} \frac{\mathrm{P}_{\mathrm{i}}^{\alpha} \mathrm{P}_{\mathrm{j}}^{\beta}}{\mathrm{d}_{\mathrm{ij}}^{\gamma}}$

Burada;

$\mathrm{t}_{\mathrm{ij}}^{\mathrm{o}}$ : $\mathrm{i}$ ilinden $\mathrm{j}$ iline gerçekleştirilen günlük otomobil yolculuklarının başlangıç için kabul edilen değeri (otomobil/gün),

$\mathrm{P}_{\mathrm{i}}$ : $\mathrm{i}$ ilinin nüfusu (kişi),

$P_{j}$ : j ilinin nüfusu (kişi),

k: bir katsay1,

$\mathrm{d}_{\mathrm{ij}}$ : i ve j illeri arasındaki mesafe $(\mathrm{km})$,

$\alpha, \beta$ ve $\gamma$ : kalibrasyon sabitleridir.

Çalışmada Çekim Modelinin en eski ve sade biçimi temel alınarak $\alpha, \beta$ ve $\gamma$ kalibrasyon sabitlerinin sirasiyla 1,1 ve 2 değerlerini aldığ 1 varsayılmıştır. Çalışmaya konu olan 81 ilin 2015 yılı nüfusları, Türkiye İstatistik Kurumu tarafından 2015 yılında gerçekleştirilen sayımların sonuçlarından elde edilmiş olup trafik kodlarıyla beraber Çizelge 1'de verilmektedir. İller arasındaki uzaklıklar, karayolu uzaklık matrisinden elde edilmiştir. 


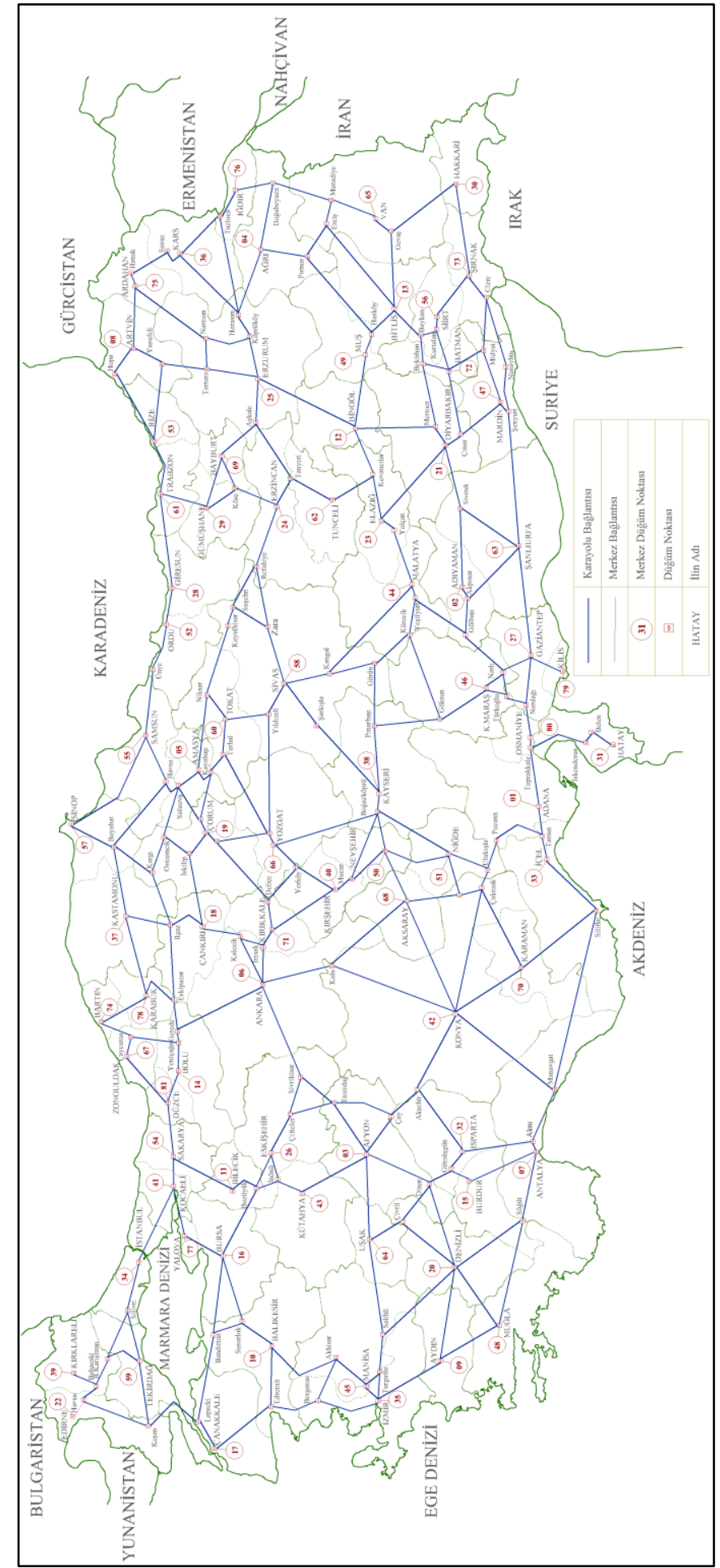

Şekil 1. 716 Bağlant1, 269 düğüm noktası ve 81 bölgeden oluşan karayolu ağ1 
$\mathrm{Bu}$ matris, Transport Programı kullanılarak teşkil edilen karayolu ağı esas alınmak suretiyle belirlenmiştir. Böylece, yukarıda değinilen çekim modeliyle teşkil edilen başlangıç matrisi ile karayolu bağlantıları üzerindeki Yıllık Ortalama
Günlük Trafik (YOGT) cinsinden verilen 2015 yılına ait otomobil sayıları Vmat Altprogramına girilerek 2015 yılı için iller arası günlük otomobil yolculuğu O-D matrisi bulunmuştur.

Çizelge 1. İllerin 2015 yılına göre nüfusları

\begin{tabular}{|c|c|c|c|c|c|c|c|c|}
\hline $\begin{array}{c}\text { İlin } \\
\text { Trafik } \\
\text { Kodu }\end{array}$ & İlin İsmi & İlin Nüfusu & $\begin{array}{c}\text { İlin } \\
\text { Trafik } \\
\text { Kodu }\end{array}$ & İlin İsmi & İlin Nüfusu & $\begin{array}{c}\text { İlin } \\
\text { Trafik } \\
\text { Kodu }\end{array}$ & İlin İsmi & İlin Nüfusu \\
\hline 1 & \begin{tabular}{|l|} 
Adana \\
\end{tabular} & 2.183 .167 & 28 & Giresun & 426.686 & 55 & \begin{tabular}{|l|} 
Samsun \\
\end{tabular} & 1.279 .884 \\
\hline 2 & Adiyaman & 602.774 & 29 & Gümüşhane & 151.449 & 56 & Siirt & 320.351 \\
\hline 3 & Afyonkarahisar & 709.015 & 30 & Hakkari & 278.775 & 57 & Sinop & 204.133 \\
\hline 4 & Ağn1 & 547.210 & 31 & Hatay & 1.533 .507 & 58 & \begin{tabular}{|l} 
Sivas \\
\end{tabular} & 618.617 \\
\hline 5 & Amasya & 322.167 & 32 & Isparta & 421.766 & 59 & Tekirdağ & 937.910 \\
\hline 6 & Ankara & 5.270 .575 & 33 & Mersin & 1.745 .221 & 60 & Tokat & 593.990 \\
\hline 7 & Antalya & 2.288 .456 & 34 & İstanbul & 14.657 .434 & 61 & Trabzon & 768.417 \\
\hline 8 & Artvin & 168.370 & 35 & İzmir & 4.168 .415 & 62 & Tunceli & 86.076 \\
\hline 9 & Aydın & 1.053 .506 & 36 & Kars & 292.660 & 63 & Şanlıurfa & 1.892 .320 \\
\hline 10 & Balıkesir & 1.186 .688 & 37 & Kastamonu & 372.633 & 64 & Uşak & 353.048 \\
\hline 11 & \begin{tabular}{|l} 
Bilecik \\
\end{tabular} & 212.361 & 38 & Kayseri & 1.341 .056 & 65 & Van & 1.096 .397 \\
\hline 12 & Bingöl & 267.184 & 39 & Kırklareli & 346.973 & 66 & Yozgat & 419.440 \\
\hline 13 & Bitlis & 340.449 & 40 & Kırşehir & 225.562 & 67 & Zonguldak & 595.907 \\
\hline 14 & Bolu & 291.095 & 41 & Kocaeli & 1.780 .055 & 68 & Aksaray & 386.514 \\
\hline 15 & Burdur & 258.339 & 42 & Konya & 2.130 .544 & 69 & Bayburt & 78.550 \\
\hline 16 & Bursa & 2.842 .547 & 43 & Kütahya & 571.463 & 70 & Karaman & 242.196 \\
\hline 17 & Çanakkale & 513.341 & 44 & Malatya & 772.904 & 71 & Kırıkkale & 270.271 \\
\hline 18 & Çankırı & 180.945 & 45 & Manisa & 1.380 .366 & 72 & \begin{tabular}{|l|} 
Batman \\
\end{tabular} & 566.633 \\
\hline 19 & Çorum & 525.180 & 46 & Kahramanmaraş & 1.096 .610 & 73 & Şırnak & 490.184 \\
\hline 20 & Denizli & 993.442 & 47 & Mardin & 796.591 & 74 & Bartın & 190.708 \\
\hline 21 & Diyarbakır & 1.654 .196 & 48 & Muğla & 908.877 & 75 & Ardahan & 99.265 \\
\hline 22 & Edirne & 402.537 & 49 & Muş & 408.728 & 76 & Iğdır & 192.435 \\
\hline 23 & \begin{tabular}{|l|} 
Elazığ \\
\end{tabular} & 574.304 & 50 & Nevşehir & 286.767 & 77 & Yalova & 233.009 \\
\hline 24 & Erzincan & 222.918 & 51 & Niğde & 346.114 & 78 & Karabük & 236.978 \\
\hline 25 & \begin{tabular}{|l|} 
Erzurum \\
\end{tabular} & 762.321 & 52 & Ordu & 728.949 & 79 & $\begin{array}{l}\text { Kilis } \\
\end{array}$ & 130.655 \\
\hline 26 & Eskişehir & 826.716 & 53 & \begin{tabular}{|l|} 
Rize \\
\end{tabular} & 328.979 & 80 & Osmaniye & 512.873 \\
\hline 27 & Gaziantep & 1.931 .836 & 54 & Sakarya & 953.181 & 81 & $\begin{array}{l}\text { Düzce } \\
\end{array}$ & 360.388 \\
\hline
\end{tabular}

2015 Y1lı Trafik ve Ulaşım Bilgileri İstatistiklerinde otomobil için YOGT değerleri, iki yönün toplamı olarak verildiğinden ve iller arası günlük otomobil yolculuğu matrisinin simetrik olması gerektiği varsayıldığından, bu değerlerin yarısı Vmat Alt Programında kullanılmıştır [20]. İllerin birbirlerine hem karayolu hem de otoyolu ile bağlanması durumunda, iller arasındaki yol kesimlerinin otomobil YOGT değeri olarak, karayolu ve otoyolu kesimlerindeki otomobil YOGT değerlerinin toplamı alınmıştır. Otoyol kesimlerinde taşıtlar ağır ve hafif araçlar olarak iki sınıfa bölündüğünden, otoyollar üzerindeki otomobil YOGT değerlerinin belirlenmesinde, hafif araçların tamamının otomobil olduğu kabul edilmiştir. O-D matrisini elde etmek için kullanılmış olan karayolu bağlantıları üzerindeki
2015 yılına ait otomobil sayıları Çizelge 2'de gösterilmektedir [20]. Elde edilen 2015 y1lına ait $81 \times 81$ boyutundaki iller aras1 otomobil yolculukları matrisinin trafik plakası numarasına göre sıralanmış ilk 12 il arasında gerçekleştirilen otomobil yolculuklarını gösteren 12x12 boyutundaki ilk kısmı, Çizelge 3 'te verilmektedir. Çizelgede birinci satırdaki numaralar ile birinci sütunda parantez içinde verilen numaralar illerin trafik plakası numarasını belirtmektedir. Yine elde edilen iller arası otomobil yolculukları matrisinin bir kısmı da, bazı il çiftleri için Çizelge 4'te gösterilmektedir. Bu çizelgede de birinci satırdaki numaralar ile birinci sütunda parantez içinde verilen numaralar illerin trafik kodunu belirtmektedir. 
Çizelge 2. Karayolu bağlantıları üzerindeki yıllık ortalama günlük trafik cinsinden otomobil sayıları

\begin{tabular}{|c|c|c|c|c|c|c|c|c|}
\hline $\begin{array}{c}\text { Kesim } \\
\text { No. }\end{array}$ & Karayolu Kesimi & $\begin{array}{c}\text { Otomobil } \\
\text { Sayısı }\end{array}$ & $\begin{array}{c}\text { Kesim } \\
\text { No. }\end{array}$ & Karayolu Kesimi & $\begin{array}{c}\text { Otomobil } \\
\text { Sayısı }\end{array}$ & $\begin{array}{c}\text { Kesim } \\
\text { No. }\end{array}$ & Karayolu Kesimi & \begin{tabular}{|c|} 
Otomobil \\
Sayısı
\end{tabular} \\
\hline 1 & \begin{tabular}{|l} 
Burdur-Isparta Ayrımı \\
\end{tabular} & 8.762 & 43 & Erzurum-Tortum & 2.033 & 85 & Antalya-Burdur & 8.043 \\
\hline 2 & İstanbul-Silivri & 45.483 & 44 & Ordu-Samsun & 13.551 & 86 & Antalya-Isparta & 4.167 \\
\hline 3 & Babaeski-Lüleburgaz & 21.113 & 45 & Ağr1-Patnos & 1.601 & 87 & Konya-Manavgat & 3.518 \\
\hline 4 & Gelibolu-Keşan & 5.995 & 46 & Iğdır-D.Beyazıt & 1.500 & 88 & Havsa-Babaeski & 10.595 \\
\hline 5 & \begin{tabular}{|l|} 
Lapseki-Bandırma \\
\end{tabular} & 3.537 & 47 & Kovancılar-Bingöl & 2.369 & 89 & \begin{tabular}{|l|} 
Tarsus-Adana \\
\end{tabular} & 34.889 \\
\hline 6 & İzmit-İstanbul & 134.833 & 48 & Akşehir-Isparta & 2.499 & 90 & Adana-Toprakkale & 21.999 \\
\hline 7 & İzmir-Manisa & 35.692 & 49 & Bayburt-Gümüşhane & 1.773 & 91 & T.Kale-İskenderun & 18.229 \\
\hline 8 & İzmit-Adapazarı & 55.704 & 50 & Gümüşhane-Trabzon & 4.930 & 92 & Osmaniye-Nurdağ1 & 18.515 \\
\hline 9 & Düzce-Bolu & 27.819 & 51 & Uşak-Salihli & 6.371 & 93 & Bingöl-Mermer & 1.176 \\
\hline 10 & Düzce-Zonguldak & 6.382 & 52 & Afyon-Uşak & 9.352 & 94 & Narl1-K.Maraş & 8.814 \\
\hline 11 & Düzce-Adapazarı & 32.422 & 53 & Afyon-Kütahya & 11.356 & 95 & Horasan-Ağr1 & 1.683 \\
\hline 12 & Narlı-Gölbaş1 & 6.394 & 54 & Kütahya-Eşkişehir Ayrımı & 12.541 & 96 & Mardin-Midyat & 2.824 \\
\hline 13 & Karabük-Bartın & 3.934 & 55 & İnegöl-Bozüyük & 11.995 & 97 & Tanyeri-Tunceli & 1.007 \\
\hline 14 & Çaycuma-Bartın & 4.814 & 56 & Çay-Akşehir & 4.972 & 98 & Ardahan-Kars & 1.274 \\
\hline 15 & Ilgaz-Kastamonu & 2.147 & 57 & Konya-Aksaray & 3.470 & 99 & Kalecik-Çankırı & 4.013 \\
\hline 16 & \begin{tabular}{|l|} 
Bayburt-Aşkale \\
\end{tabular} & 1.125 & 58 & Çakmak-Ulukışla & 9.462 & 100 & Çankır1-İskilip & 2.102 \\
\hline 17 & Gerede-Eskipazar & 9.073 & 59 & Kovanc1lar-Tunceli & 1.318 & 101 & Merzifon-Çorum & 7.555 \\
\hline 18 & Karabük-Kastamonu & 3.169 & 60 & Konya-Karaman & 4.074 & 102 & Tokat-Turhal & 6.605 \\
\hline 19 & Kastamonu-Boyabat & 3.289 & 61 & Ulukışla-Pozant1 & 10.620 & 103 & Kırıkkale-Kırşehir & 7.595 \\
\hline 20 & Sinop-Samsun & 2.425 & 62 & Niğde-Kayseri & 4.309 & 104 & Aksaray-Çakmak & 4.665 \\
\hline 21 & \begin{tabular}{|l} 
Havsa-Samsun \\
\end{tabular} & 14.650 & 63 & Aksaray-Nevşehir & 4.807 & 105 & Kayseri-Pınarbaş1 & 4.493 \\
\hline 22 & Ordu-Giresun & 13.615 & 64 & Niğde-Nevşehir & 2.117 & 106 & Muş-Hasköy & 2.044 \\
\hline 23 & Giresun-Trabzon & 10.063 & 65 & Kayseri-Yozgat & 2.728 & 107 & Refahiye-Erzincan & 1.836 \\
\hline 24 & Trabzon-Rize & 10.264 & 66 & Malatya-Doğanşehir & 2.909 & 108 & Uşak-Çivril & 2.532 \\
\hline 25 & Rize-Hopa & 3.913 & 67 & Gaziantep-Şanlıurfa & 13.401 & 109 & Erzincan-Köse & 1.177 \\
\hline 26 & Artvin-Ardahan & 964 & 68 & Adıyaman-Şanlıurfa & 3.036 & 110 & Tercan-Aşkale & 1.839 \\
\hline 27 & \begin{tabular}{|l|} 
Iğdır-Tuzluca \\
\end{tabular} & 932 & 69 & Şanlıurfa-Şenyurt & 2.714 & 111 & Ankara-Kulu & 11.975 \\
\hline 28 & Köprüköy-Horasan & 2.885 & 70 & Siverek-Diyarbakır & 4.229 & 112 & Denizli-Dinar & 7.041 \\
\hline 29 & Çanakkale-Edremit & 5.065 & 71 & Mersin-Erdemli & 5.094 & 113 & Sivrihisar-Ankara & 12.572 \\
\hline 30 & Akhisar-Balıkesir & 9.196 & 72 & Diyarbakır-Çınar & 8.117 & 114 & Dinar-Afyon & 8.493 \\
\hline 31 & Balıkesir-Susurluk & 10.440 & 73 & Şırnak-Siirt & 416 & 115 & Gaziantep-Kilis & 3.085 \\
\hline 32 & Bursa-Yalova & 34.280 & 74 & Batman-Kurtalan & 2.726 & 116 & Sivas-Yıldızeli & 5.414 \\
\hline 33 & \begin{tabular}{|l|} 
Bilecik-Adapazarı \\
\end{tabular} & 9.424 & 75 & Bitlis-Baykan & 1.938 & 117 & Delice-Ankara & 25.485 \\
\hline 34 & Ankara-Gerede & 17.101 & 76 & Bitlis-Gevaş & 1.519 & 118 & Kırşehir-Mucur & 7.793 \\
\hline 35 & Delice-Çorum & 8.267 & 77 & Gevaş-Hakkari & 735 & 119 & Bozüyük-Eskişehir & 12.800 \\
\hline 36 & Kayseri-Şarkışla & 3.972 & 78 & İzmir-Aydın & 32.223 & 120 & Yerköy-Yozgat & 4.733 \\
\hline 37 & Sivas-Kangal & 1.249 & 79 & Aydın-Denizli & 9.699 & 121 & Yalova-İzmit & 32.254 \\
\hline 38 & \begin{tabular}{|l|} 
Malatya-Elazığ \\
\end{tabular} & 4.842 & 80 & Denizli-Salihli & 5.000 & 122 & Hakkari-Şırnak & 493 \\
\hline 39 & Elazığ-Diyarbakır & 2.886 & 81 & Boyabat-Havsa & 2.599 & 123 & Denizli-Muğla & 2.773 \\
\hline 40 & Silvan-Mermer & 2.329 & 82 & Aydın-Muğla & 11.843 & 124 & Karabük-Eskipazar & 3.776 \\
\hline 41 & Bingöl-Muş & 2.162 & 83 & Altınyayla-Muğla & 5.162 & 125 & Nevşehir-Kayseri & 4.974 \\
\hline 42 & Bingöl -Erzurum & 2.348 & 84 & Altınyayla-Denizli & 3.315 & & & \\
\hline
\end{tabular}

Çizelge 3. 2015 Yılına ait $81 \times 81$ boyutundaki iller arası otomobil yolculukları matrisinin trafik plakası numarasına göre sıralanmış ilk 12 il arasında gerçekleştirilen otomobil yolculuklarını gösteren 12x12 boyutundaki ilk kısmı

\begin{tabular}{|l|c|c|c|c|c|c|c|c|c|c|c|c|}
\hline İller & $\mathbf{1}$ & $\mathbf{2}$ & $\mathbf{3}$ & $\mathbf{4}$ & $\mathbf{5}$ & $\mathbf{6}$ & $\mathbf{7}$ & $\mathbf{8}$ & $\mathbf{9}$ & $\mathbf{1 0}$ & $\mathbf{1 1}$ & $\mathbf{1 2}$ \\
\hline Adana (1) & 0 & 111 & 14 & 8 & 7 & 265 & 245 & 11 & 56 & 8 & 4 & 6 \\
\hline Adıyaman (2) & 111 & 0 & 2 & 5 & 1 & 47 & 27 & 1 & 8 & 2 & 2 & 1 \\
\hline Afyonkarahisar (3) & 14 & 2 & 0 & 1 & 3 & 344 & 281 & 13 & 118 & 55 & 47 & 1 \\
\hline Ağrı (4) & 8 & 5 & 1 & 0 & 1 & 16 & 9 & 64 & 2 & 0 & 0 & 19 \\
\hline Amasya (5) & 8 & 1 & 3 & 1 & 0 & 105 & 7 & 27 & 4 & 1 & 1 & 0 \\
\hline Ankara (6) & 265 & 47 & 345 & 16 & 105 & 0 & 353 & 82 & 185 & 112 & 107 & 11 \\
\hline Antalya (7) & 246 & 27 & 281 & 9 & 7 & 353 & 0 & 12 & 496 & 97 & 39 & 3 \\
\hline Artvin (8) & 11 & 1 & 14 & 63 & 28 & 83 & 12 & 0 & 26 & 5 & 13 & 26 \\
\hline Aydın(9) & 55 & 8 & 118 & 2 & 4 & 185 & 496 & 26 & 0 & 130 & 19 & 3 \\
\hline Balikesir(10) & 8 & 2 & 56 & 0 & 1 & 112 & 97 & 5 & 131 & 0 & 16 & 1 \\
\hline Bilecik (11) & 4 & 2 & 47 & 0 & 1 & 107 & 39 & 13 & 19 & 16 & 0 & 1 \\
\hline Bingö1 (12) & 6 & 1 & 1 & 19 & 0 & 11 & 3 & 25 & 3 & 1 & 1 & 0 \\
\hline
\end{tabular}


Çizelge 4. Bazı il çiftleri için regresyon analizine dayalı çekim esaslı yolculuk dağıtımı modelinden elde edilen otomobil yolculukları ve gözlenmiş otomobil yolculukları

\begin{tabular}{|l|l|c|c|c|c|c|c|c|c|c|c|}
\hline İller & & $\mathbf{1}$ & $\mathbf{6}$ & $\mathbf{1 6}$ & $\mathbf{2 1}$ & $\mathbf{3 4}$ & $\mathbf{3 5}$ & $\mathbf{3 8}$ & $\mathbf{4 2}$ & $\mathbf{4 4}$ & $\mathbf{5 5}$ \\
\hline \multirow{2}{*}{ Adana (1) } & Gözlenmiş & 0 & 265 & 38 & 50 & 159 & 43 & 174 & 223 & 48 & 28 \\
& Regresyon Modeli & 0 & 246 & 69 & 106 & 166 & 81 & 184 & 237 & 108 & 50 \\
\hline \multirow{2}{*}{ Ankara (6) } & Gözlenmiş & 265 & 0 & 871 & 52 & 2.785 & 495 & 765 & 2.128 & 65 & 329 \\
& Regresyon Modeli & 246 & 0 & 441 & 77 & 931 & 293 & 378 & 720 & 82 & 224 \\
\hline \multirow{2}{*}{ Bursa (16) } & Gözlenmiş & 38 & 868 & 0 & 12 & 8.313 & 179 & 72 & 179 & 12 & 22 \\
& Regresyon Modeli & 69 & 441 & 0 & 29 & 1.677 & 500 & 69 & 163 & 26 & 58 \\
\hline \multirow{2}{*}{ Diyarbakır (21) } & Gözlenmiş & 50 & 52 & 12 & 0 & 51 & 5 & 29 & 11 & 137 & 20 \\
& Regresyon Modeli & 106 & 77 & 29 & 0 & 76 & 32 & 63 & 45 & 167 & 34 \\
\hline \multirow{2}{*}{ İstanbul (34) } & Gözlenmiş & 157 & 2.757 & 8.373 & 50 & 0 & 393 & 278 & 266 & 48 & 265 \\
& Regresyon Modeli & 166 & 930 & 1.677 & 76 & 0 & 582 & 171 & 282 & 66 & 177 \\
\hline \multirow{2}{*}{ İzmir (35) } & Gözlenmiş & 43 & 496 & 179 & 5 & 391 & 0 & 42 & 189 & 8 & 35 \\
& Regresyon Modeli & 81 & 293 & 500 & 32 & 582 & 0 & 65 & 178 & 27 & 48 \\
\hline \multirow{2}{*}{ Kayseri (38) } & Gözlenmiş & 174 & 766 & 73 & 29 & 281 & 42 & 0 & 259 & 57 & 66 \\
& Regresyon Modeli & 184 & 378 & 70 & 63 & 171 & 65 & 0 & 222 & 99 & 83 \\
\hline \multirow{2}{*}{ Konya (42) } & Gözlenmiş & 223 & 2.130 & 180 & 11 & 266 & 189 & 259 & 0 & 21 & 64 \\
& Regresyon Modeli & 237 & 721 & 163 & 45 & 283 & 178 & 222 & 0 & 47 & 59 \\
\hline \multirow{2}{*}{ Malatya (44) } & Gözlenmiş & 48 & 65 & 12 & 137 & 48 & 8 & 57 & 21 & 0 & 25 \\
& Regresyon Modeli & 108 & 82 & 26 & 167 & 66 & 27 & 99 & 47 & 0 & 38 \\
\hline \multirow{2}{*}{ Samsun (55) } & Gözlenmiş & 28 & 325 & 22 & 20 & 261 & 35 & 65 & 63 & 25 & 0 \\
& Regresyon Modeli & 50 & 224 & 58 & 34 & 177 & 48 & 83 & 59 & 38 & 0 \\
\hline
\end{tabular}

\section{OTOMOBIL YOLCULUKLARININ ÇOKLU REGRESYON ANALIZIYLE MODELLENMESİ}

İller arası otomobil yolculukları matrisinin bulunmasindan sonra, bu matristen elde edilen $\mathrm{O}$ D bilgileri için çoklu regresyon analizi gerçekleştirilmiştir. Bu analizin gerçekleştirilmesi için Excel programı kullanılmıştır. Pearson yöntemi, analizde değişkenler arasındaki korelasyon katsayısının belirlenmesinde kullanılmıştır. Parametrelerin anlamlılık düzeyleri için $\mathrm{p}<0,05$ olması gerektiği kabul edilmiştir. Burada iller arasında gerçekleştirilen otomobil yolculukları bağımlı değişken olarak alınırken, illerin nüfusları ve aralarındaki uzaklıklar ise bağımsız değişkenler olarak alınmıştır. Analizde, parametreler arasındaki ilişkinin, başlangıç matrisindeki gibi olduğu varsayılmıştır. Bu ilişki ise, aşağıda verilmektedir: (Eşitlik 9)

$\overline{T_{i j}}=k \frac{P_{i}^{\alpha}{ }^{\beta}{ }_{j}^{\beta}}{d_{i j}^{\gamma}}$

Burada;

$\overline{T_{i j}}$ : i ilinden $\mathrm{j}$ iline gerçekleştirilen günlük otomobil yolculukları (otomobil/gün),
$\mathrm{P}_{\mathrm{i}}$ : i ilinin nüfusu (kişi),

$P_{\mathrm{j}}: \mathrm{j}$ ilinin nüfusu (kişi),

$\mathrm{k}$ : bir katsay1,

$\mathrm{d}_{\mathrm{ij}}$ : i ve j illeri arasındaki mesafe $(\mathrm{km})$,

$\alpha, \beta$ ve $\gamma$ : kalibrasyon sabitleridir.

Yukarıda verilen eşitlik, çoklu doğrusal regresyon analizini gerçekleştirmek için, eşitliğin her iki tarafının logaritması alınarak doğrusal hale getirilmiştir. Analizde kullanılan tüm parametreler sayısal olup, bağımlı değişken olarak iller arasında gerçekleştirilen otomobil yolculukları (otomobil/gün), bağımsız değişkenler olarak ise illerin nüfusları (kişi) ile aralarındaki mesafeler (km) alınmıştır. Bu işlem, Eşitlik 10, 11 ve 12'de gösterilmiştir:

$\log \left(\overline{T_{i j}}\right)=\log \left(k \frac{P_{i}^{\alpha}{ }_{j}^{\beta}}{d_{i j}^{\gamma}}\right)$

$\log \left(\overline{T_{i j}}\right)=\log (k)+\alpha \cdot \log \left(P_{i}\right)+\beta \cdot \log \left(P_{j}\right)-$

$-\gamma \cdot \log \left(d_{i j}\right)$ 


$$
Y=A+\alpha \cdot X_{1}+\beta \cdot X_{2}-\gamma \cdot X_{3}
$$

İller arasında gerçekleştirilen otomobil yolculuklarını belirlemek için yapılan çoklu regresyon analizinde, bağımsız değişkenlerin katsayıları belirlenmiştir. İlk olarak, varyans analizinin gerçekleştirilmesiyle, bağımlı değişkenin bağımsı değişkenler tarafindan açıklanıp açıklanmadığı, başka bir deyişle, bağımlı değişkenle bağımsız değişkenler arasında doğrusal bir ilişkinin olup olmadığı test edilmiştir [21]. Bu analiz için F testi gerçekleştirilmiş ve sonucun anlamlı olduğu anlaşılmıştır. Parametrelerin anlamlılıkları ise, Student testi ile araştırılmış ve anlamlılık 0,05'den küçük bulunmuştur.

Gerçekleştirilen çoklu regresyon analizi, uygunluk değerini (r kare değeri) 0,667434 olarak vermiştir. Buna ek olarak, $\alpha, \beta$ ve $\gamma$ kalibrasyon sabitleri sirasiyla $0,64409,0,644288$ ve 1,84626 olarak bulunmuştur. $\mathrm{Bu}$ analizden, $\mathrm{k}$ sabiti ise 0,021426932 olarak elde edilmiştir.

Daha sonra, bu regresyon analizinden elde edilen bağımsız değişkenlerin katsayıları, yolculuk dağıtımı modelinin kalibrasyon sabitleri olarak kullanılmıştır. $\mathrm{Bu}$ sabitler, iller arasında gerçekleştirilen otomobil yolculuklarını illerin nüfuslarına ve aralarındaki uzaklığa bağlı olarak belirleyen yukarıdaki denklemde yerleştirilerek, çekim esaslı yolculuk dağıtımı modeli geliştirilmiştir. Böylece, otomobil yolculukları için ikinci bir matris belirlenmiştir. $\mathrm{Bu}$ matrisin elemanları, çekim esaslı yolculuk dağıtımı modelinin tahmin ettiği iller arası otomobil yolculuklarının sayısını göstermektedir. Bazı il çiftleri için, iller arasında gerçekleştirilen otomobil yolculuklarını tahmin etmek üzere çoklu regresyon yöntemi kullanılarak geliştirilen modelden elde edilen sonuçlar, Vmat Alt Programı tarafindan bulunan günlük gözlenmiş otomobil yolculukları ile birlikte karşılaştırma yapmak amacıyla Çizelge 4'te verilmektedir. Çizelge 4'teki çoğu il çifti için, çoklu regresyon yöntemiyle geliştirilen modelin, iller arasinda yapilan otomobil yolculuklarını gözlenmiş otomobil yolculuklarına oldukça yakın bir şekilde tahmin ettiği görülmektedir. Ancak, çekim esaslı bu model, özellikle Türkiye'nin batısındaki büyük nüfuslu iller arasında gerçekleştirilen çok sayıdaki otomobil yolculuklarını iyi tahmin edememektedir.

\section{4. ÍLLER ARASI OTOMOBIL YOLCULUKLARI MATRISININ CBS ORTAMINA AKTARILMASI}

Coğrafi Bilgi Sistemleri (CBS), konuma dayalı gözlemlerden elde edilen grafiksel ve grafiksel olmayan bilgilerin toplanması, depolanması, işlenmesi, gösterilmesi ve analizi için kullanılan bilgisayar tabanlı sistemlerdir. CBS tarafindan sağlanan çok yönlü fonksiyonellik, bu teknolojiyi eski teknolojilerden ayırmaktadır. Çok yönlü fonksiyonelliğin bir ortamda sağlanması, kullanıcıların birbirinden tamamen farklı ve özelleşmiş teknolojilerin hepsine birden hâkim olmaları ihtiyacını ortadan kaldırır. Sahip olduğu bu özellikler sayesinde de, pek çok disiplinler arası araştırma ve uygulama çalışmalarında uygun bir yöntem olarak kullanılmaktadır. Günümüzde bu yöntem, sağlık, jeoloji, çevre, ziraat, sosyoloji ve ulaşım gibi pek çok bilim dalında kendine uygulama alanı bulmuştur. Sonuç olarak, birçok organizasyon, benzersiz özelliklerinden dolay1 CBS teknolojisini benimsemiştir [22].

Son yıllarda CBS teknolojisinin ulaşım alanında kullanımıyla ilgili olmak üzere, ülkelerin ulaşım politikalarını iyileştirmek ve geliştirmek amacıyla karar destek aracı olarak kullanımına yönelik örneklere rastlanmaktadır. Ulaşım ağlarındaki kapasite miktarlarının ve ağların günlük kullanımlarının tespit edilip kapasite kullanım oranlarının çıkarılması, CBS teknolojisi ile karar vericilere hızlı ve doğru kararlar aldırmaktadır.

Başka bir deyişle, mekânsal sorgulamalar sonucu oluşturulan tematik haritalarla yol ağlarının kapasite kullanım oranları tespit edilebilmektedir. Ayrıca, mekânsal veriyle oluşturulan haritalar, şehir veya devlet yolları üzerinde oluşabilecek yıpranmalarla ilgili olarak, karar vericilere önemli bilgiler verebilmektedir. 2005 Yılında Ulaştırma Bakanlığı'nın isteğiyle İstanbul Teknik Üniversitesi tarafından hazırlanan "Ulaştırma Ana Planı Stratejisi” Sonuç Raporu'nda, CBS 
teknolojisi, veri tabanları ve proje bazlı çözümler gibi diğer teknolojiler ile karşılaştırıldığında, ulaştırma alanında faaliyet gösteren kurumlar tarafından geri dönüşüm potansiyeli en yüksek olan bilgi teknolojisi olarak tanımlanmıştır [23]

Elde edilen verilerin daha sağlıklı ve uygun bir şekilde analiz edilmesi için, iller arası otomobil yolculukları matrisi, CBS ortamına aktarılmıştır. Bunun için, ileri düzeydeki programlama dilleri kullanılarak yazılmış bir program olan MapInfo yazılımından yararlanılmıştır. Bu amaçla, öncelikle dijitalleştirilmiş bir Türkiye haritası kullanılmıştır. $\mathrm{Bu}$ harita üzerinde Türkiye'deki 81 ilin tamamı oluşturulmuştur. Ayrıca, her ile aynı zamanda o ilin plaka numarası olan bir kod numarası verilmiştir. Daha sonra, 2015 yılına ait iller arası otomobil yolculuğu matrisi, CBS analizlerini gerçekleştirmek için MapInfo yazılımına uygun bir formata dönüştürülmüştür. Böylece, O-D matrisini görsel bir ortamda görmek ve bu iller arasında karşılaştırma ve sorgulama analizlerini gerçekleştirmek mümkün olmuştur.

Hazırlanan tematik haritalardan biri, Şekil 2'de verilmektedir. Bu şekil, Ankara'dan diğer illere yapılan günlük otomobil yolculuklarının sayısını tematik olarak göstermektedir. Benzer şekilde, Şekil 3 ve Şekil 4'te İstanbul ve Trabzon'dan diğer illere gerçekleştirilen günlük otomobil yolculuklarını gösteren haritalar verilmektedir. Şekillerden de görülebileceği gibi, renkler koyudan açığa doğru gittikçe, diğer illere yapılan günlük otomobil yolculuklarının sayısı azalmaktadır.

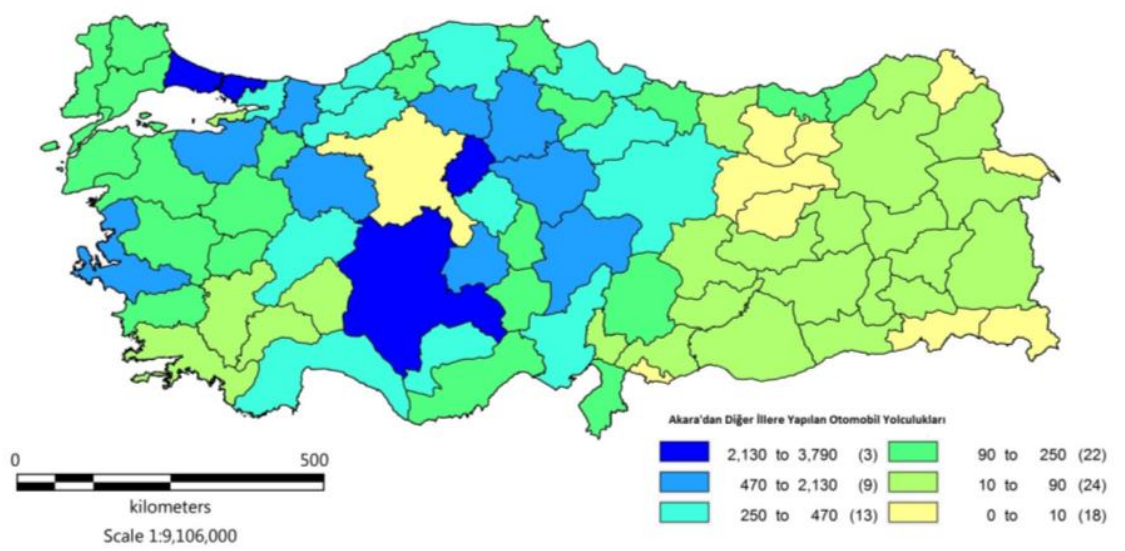

Şekil 2. Ankara'dan diğer illere yapılan otomobil yolculukları

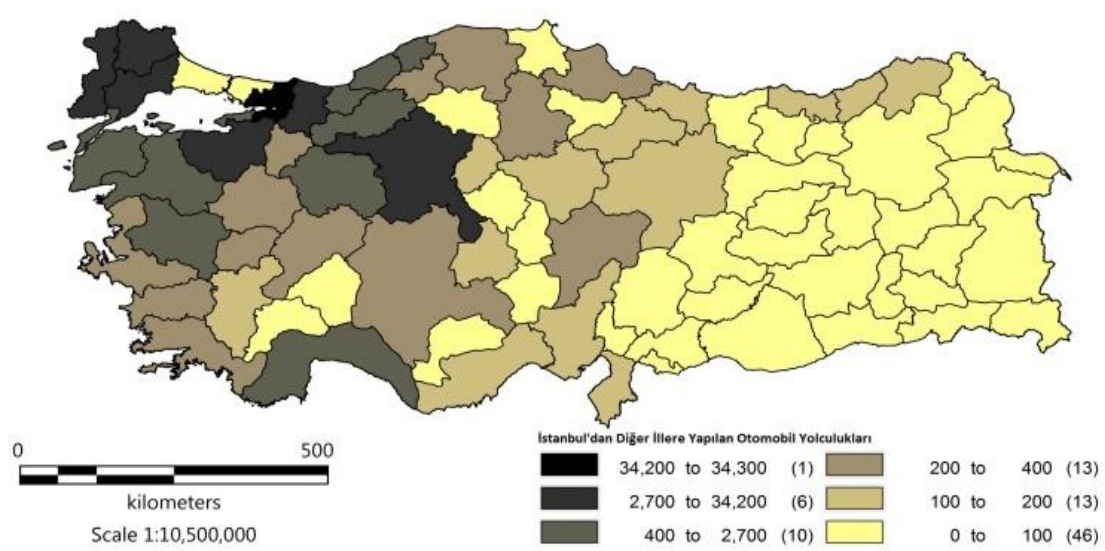

Şekil 3. İstanbul'dan diğer illere yapılan günlük otomobil yolculukları 


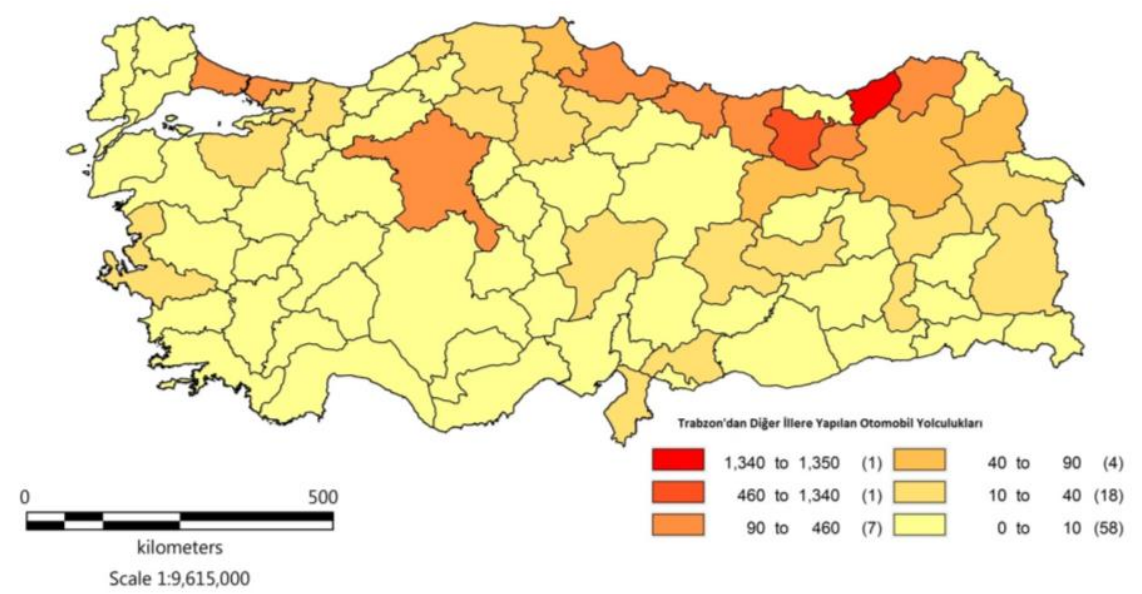

Şekil 4. Trabzon'dan diğer illere yapılan otomobil yolculukları

\section{SONUÇLAR}

O-D matrislerini tahmin etmek için birçok yöntem kullanılmasına rağmen, trafik bilgilerini, nüfusları ve mesafeleri kullanmakta olan önerilen yöntem, pahalı ve zaman alıcı değildir. Buna ek olarak, elde edilen O-D matrisleri, ilgili trafik bilgilerini, nüfusları ve mesafeleri kullanmak suretiyle, herhangi bir planlama aşaması için, bu yöntemle kolaylıkla güncellenebilir. Önerilen yöntem, iller arası otomobil yolculuklarını tahmin etme hususunda oldukça iyi bir performansa sahip olduğunu kanıtlamıştır. Bu çalışmada, iller arası otomobil yolculukları için uygunluk değeri (r kare değeri) 0,667434 olarak bulunmuş olup, oldukça kabul edilebilir bir düzeydedir. Bu çalışmanın bir diğer önemli katkısı, uygulamada çalışan mühendislerin O-D matrislerinin elde ediliş şeklini anlamalarına yardımcı olmasıdır. Bu çalışma, aynı zamanda onlara, daha iyi planlar yapmaları için kullanabilecekleri yararlı verileri vermektedir. Bundan başka, geliştirilen yöntem, iller arası otomobil taşımasıyla ilgili uzun vadeli politikaları belirlemek için kullanılabilir. Karar vericiler, planlama ve etkin politikaların oluşturulması aşamalarında, uygun bir bilgi sistemine ihtiyaç duyarlar. CBS, bu amaçla kullanılabilecek etkili bir araçtır. Verileri, tablolar şeklinde dikkate almak yerine, bilgisayar üzerinde coğrafi koordinatlarıyla göz önüne almak ve analiz etmek, kesinlikle daha faydalı ve etkilidir. Bu yüzden, iller arası otomobil yolculukları matrisi, analizleri daha etkin bir şekilde gerçekleştirmek amacıyla CBS ortamına aktarılmıştır.

\section{KAYNAKLAR}

1. Bell, M.G.H., 1983. The Estimation of OriginDestination Flows and their Confidence Intervals from Measurements of Link Volumes: a Computer Program, Traffic Engineering and Control 24, 202-205.

2. Bell, M.G.H., 1983. The Estimation of an Origin-Destination Matrix from Traffic Counts, Transportation Science 17, 198-217.

3. Ortuzar, J. de D., Willumsen, L.G., 2011. Modelling Transport (Third Edition), John Wiley and Sons Inc., New York, 607.

4. Robillard, P., 1975. Estimating the O-D Matrix from Observed Link Volumes, Transportation Research 9, 123-128.

5. Hogberg, P., 1976. Estimation of Parameters in Models for Traffic Prediction: a Non-linear Approach, Transportation Research 10, 263-265.

6. LeBlanc, L.J., 1982. Selection of a Trip Table Which Reproduces Observed Link Flows, Transportation Research (B) 16, 83-88.

7. Wilson, A.G., 1970. Interregional Commodity Flows: Entropy Maximizing Procedures, Geographical Analysis 2, 255-282.

8. Van Zuylen, H.J., Willumsen, L.G., 1980. The Most Likely Trip Matrix Estimated from 
Traffic Counts, Transportation Research (B) 14, 281-293.

9. McNeil, S., Hendrickson, C., 1985. A Note on Alternative Matrix Entry Estimation Techniques, Transportation Research (B) 19, 509-519.

10. Cascetta, E., 1984. Estimation of Trip Matrices from Traffic Counts and Survey Data: A Generalized Least Squares Estimator, Transportation Research (B) 18, 289-299.

11. Mahmassani, H.S., Sinha, K., 1981. A Bayesian Updating of Trip Generation Parameters, Journal of Transportation Engineering 107, 581-589.

12. Yang, H., 1995. Heuristic Algorithms for the Bi-Level Origin-Destination Matrix Estimation Problem, Transportation Research (B) 29, 231-242.

13. Ashok, K., Ben-Akiva, M.E., 2000. Alternative Approaches for Real-Time Estimation and Prediction of Time-Dependent OriginDestination Flows, Transportation Science 34(1), 21-36.

14.Zhou, X., Qin, X., Mahmassani, H.S., 2003. Dynamic Origin-Destination Demand Estimation Using Multi-Day Link Traffic Counts for Planning Applications, Transportation Research Record 1831, 30-38.

15. Cheung, W.M., Wong, S.C., Tong, C. O., 2006. Estimation of a Time-Dependent OriginDestination Matrix for Congested Highway Networks, Journal of Advanced Transportation 40, 95-117.

16.Lu, Z., Rao, W., Wu, Y.J., Guo, L., Xia, J., 2015. A Kalman Filter Approach to Dynamic of Flow Estimation for Urban Road Networks Using Multi-Sensor Data, Journal of Advanced Transportation 49, 210-227.

17. http://www.tuik.gov.tr

18. http://www.kgm.gov.tr

19. Transport User Guide, 1986. Micro Computer Transportation Planning Package, Halcrow Fox and Associates, London, England.

20.2015 Trafik ve Ulaşım Bilgileri, 2016. Ulaşım Etütleri Şubesi Müdürlüğü, Türkiye Cumhuriyeti Karayolları Genel Müdürlüğü (KGM), Ankara, Türkiye.
21. Özdamar, K., 1999. Paket Programlarla İstatistiksel Veri Analizi (İkinci Bask1), Kaan Yayın Evi, Eskişehir, 423-446.

22. Yomralığlu, T., 2000. Coğrafi Bilgi Sistemleri (İkinci Bask1), Secil Ofset, Istanbul, 45-58.

23. Ulaştırma Ana Planı Stratejisi Sonuç Raporu, 2005. T.C. Ulaştırma Bakanlığı ve İstanbul Teknik Üniversitesi Ulaştırma ve Ulaşım Araçları Uyg-Ar Merkezi, Türkiye. 
